\title{
Opioid Limbic Circuit for Reward: Interaction between Hedonic Hotspots of Nucleus Accumbens and Ventral Pallidum
}

\author{
Kyle S. Smith and Kent C. Berridge \\ Department of Psychology, University of Michigan, Ann Arbor, Michigan 48109
}

\begin{abstract}
$\mu$-Opioid stimulation of cubic millimeter hedonic hotspots in either the nucleus accumbens shell (NAc) or the ventral pallidum (VP) amplifies hedonic "liking" reactions to sweetness and appetitive "wanting" for food reward. How do these two NAc-VP hotspots interact? To probe their interaction and limbic circuit properties, we assessed whether opioid activation of one hotspot recruited the other hotspot (neurobiologically) and whether opioid hedonic and incentive motivational amplification by either opioid hotspot required permissive opioid coactivation in the other (behaviorally). We found that NAc and VP hotspots reciprocally modulated Fos expression in each other and that the two hotspots were needed together to enhance sucrose "liking" reactions, essentially cooperating within a single hedonic NAc-VP circuit. In contrast, the NAc hotspot dominated for opioid stimulation of eating and food intake ("wanting"), independent of VP activation. This pattern reveals differences between limbic opioid circuits that control reward "liking" and "wanting" functions.
\end{abstract}

Key words: nucleus accumbens; ventral pallidum; opioid, hedonic; reward; motivation; eating; food intake; Fos

\section{Introduction}

Excessive consumption of rewards is a feature of obesity, drug addiction, and related problems involving compulsive pursuit of incentives. $\mu$-Opioid hotspots in the nucleus accumbens (NAc) and ventral pallidum (VP) help generate both reward hedonic impact ("liking") and incentive motivation ("wanting") for food, addictive drugs, and other rewards (Cooper and Kirkham, 1993; Yeomans and Gray, 1996; Drewnowski, 1997; Berthoud, 2002; Kelley et al., 2002; Berridge, 2003; Koob, 2003; Robinson and Berridge, 2003; Bodnar, 2004; Levine and Billington, 2004; Everitt and Robbins, 2005; Kalivas and Volkow, 2005; Kelley et al., 2005; Beaver et al., 2006; Peciña et al., 2006).

The NAc contains a hedonic hotspot, $1.0 \mathrm{~mm}^{3}$ in volume, in the rostrodorsal medial shell in which $\mu$-opioid stimulation generates increases in both "wanting" and "liking" for food reward (Peciña and Berridge, 2005). The VP contains a similar hedonic hotspot in its posterior sector, $0.8 \mathrm{~mm}^{3}$ in volume (Smith and Berridge, 2005; Peciña et al., 2006). In both of those hedonic hotspots, microinjection of a $\mu$-opioid agonist amplifies positive orofacial reactions elicited by the hedonic impact of sucrose taste (e.g., tongue protrusions) that are homologous to the affective facial "liking" expressions of primates and human infants (Berridge, 2000; Steiner et al., 2001; Peciña and Berridge, 2005; Smith and Berridge, 2005). Opioid stimulation in the NAc and

\footnotetext{
Received Sept. 26, 2006; revised Dec. 6, 2006; accepted Jan. 2, 2007.

This work was supported by National Institutes of Health (NIH) Grants DA015188 and MH63649 (K.C.B.). K.S.S. was supported by NIH Training Grant DCO0011. We thank Philip Hoberg for help with experiments and Sarah W. Newman for advice on neuroanatomy.

Correspondence should be addressed to Kyle S. Smith, Department of Psychology, 530 Church Street, Ann Arbor, MI 48109-1109. E-mail: kyless@umich.edu.

DOI:10.1523/JNEUROSCI.4205-06.2007

Copyright $\odot 2007$ Society for Neuroscience $\quad$ 0270-6474/07/271594-12\$15.00/0
}

VP hedonic hotspots also increase motivational "wanting" for food, as reflected by increased eating behavior, as does opioid stimulation of a larger region surrounding the NAc hotspot (but without enhancing "liking" reactions to taste) (Zhang et al., 1998; Peciña and Berridge, 2000; Peciña and Berridge, 2005; Smith and Berridge, 2005; Shimura et al., 2006; Woolley et al., 2006).

The NAc sends compressed output projections to the VP (Heimer and Wilson, 1975; Mogenson and Yang, 1991; Zahm, 2000), and reciprocal projections also exist from the VP back to the NAc (Churchill and Kalivas, 1994). Each structure is also embedded in larger, complex mesocorticolimbic loop circuits involving the lateral hypothalamus ( $\mathrm{LH})$, ventral tegmentum, prefrontal cortex, amygdala, and other structures, providing additional routes for control of reward functions (Haber et al., 1985; Grove, 1988a,b; Groenewegen et al., 1993; Swanson, 2000; Kelley et al., 2005). However, little is known about how hedonic hotspots in the NAc and VP interact together to form larger limbic circuits that control "liking" or "wanting" for rewards.

Here we assessed neurobiological and functional interaction between NAc and VP hotspots. We asked whether opioid modulation of one hotspot recruited in turn changes in c-fos translation into Fos protein in the other and whether "liking" or "wanting" enhancement by either opioid hotspot required permissive opioid activity in the other. We found that NAc and VP hotspots can reciprocally activate or inhibit neurobiological activity in each other. We also found that enhancement of hedonic "liking" reactions to sucrose requires unanimous opioid participation simultaneously by both NAc and VP hotspots. In contrast, for opioidstimulated food "wanting," the NAc hotspot exerts dominant or independent control. Thus, different circuits appear to mediate opioid generation of reward "liking" versus "wanting" functions, even when stimulated from the same limbic hotspots. 


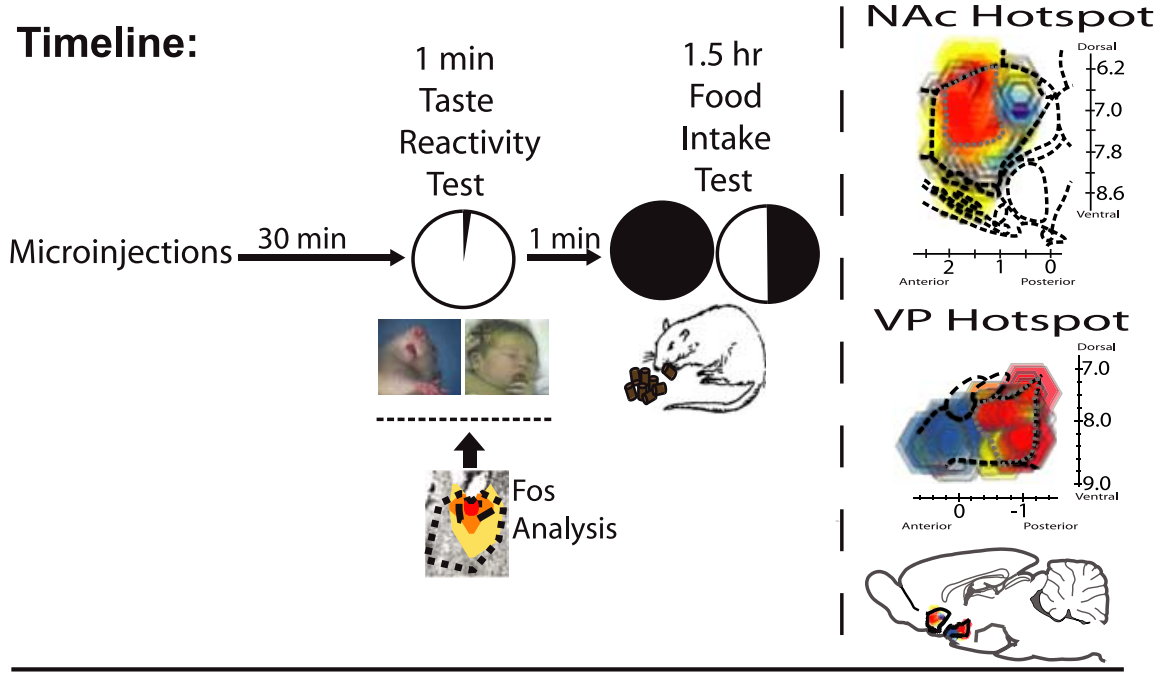

Condition:

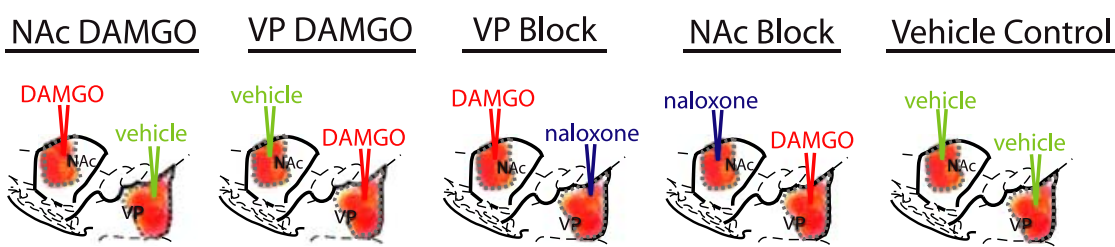

Figure 1. Experimental timeline and microinjection combinations. At time 0 , rats were microinjected simultaneously in the NAc and VP with one of five combinations of drugs or vehicle centered in the hedonic hotspots shown in the top right (combinations depicted in "conditions" at bottom). For each combination, one drug (DAMG0 or naloxone) or vehicle was administered bilaterally in NAc, and a different drug or vehicle was administered bilaterally in VP. A taste reactivity test of "liking" reactions to orally infused sucrose ( $1 \mathrm{~min}$ ) was conducted at $30 \mathrm{~min}$ after microinjection (homologous tongue protrusion to sucrose shown in rat and human infant). Immediately after taste reactivity, spontaneous food intake was measured for the next $1.5 \mathrm{~h}$. Fos plumes and distant Fos expression was assessed in separate rats, corresponding approximately to time of taste reactivity test and the onset of food intake test (Fos plume image, DAMG0). NAc and VP hotspots are modified from Peciña and Berridge (2005) and Smith and Berridge (2005).

\section{Materials and Methods}

We will use "liking" as a shorthand to refer to enhancement of orofacial reactions to taste that reflect positive hedonic impact (e.g., tongue protrusions and lateral tongue protrusions) without enhancement of neutral or aversive reactions and use "wanting" as shorthand for enhanced food intake and eating behavior. We examined whether $\mu$-opioid antagonist (naloxone) microinjection in the VP hotspot would block increases in hedonic "liking" reactions and/or food "wanting" normally caused by $\mu$-opioid agonist [D-Ala2-N-Me-Phe ${ }^{4}$-glycol ${ }^{5}$-enkephalin (DAMGO)] microinjection in the NAc hotspot. In reverse, we examined whether naloxone in the NAc would block "liking" and/or "wanting" increases normally caused by DAMGO in the VP hotspot. We further measured local Fos plumes induced by each type of opioid microinjection, used them to map "liking" and "wanting" substrates in the NAc or VP, and examined whether opioid feedback between sites influenced local Fos plumes generated by DAMGO microinjection. Finally, to assess neurobiological interactions between NAc and VP hotspots that might control "liking" and "wanting," we measured distant Fos changes in the opposite hedonic hotspot caused by microinjections of DAMGO or naloxone.

Experiment design (see Fig. 1). We used a split-and-recombine design to compare behavioral and neurobiological effects of drug microinjections. Rats were assigned to either behavioral or Fos analysis groups at the time of surgery, and the same surgical coordinates were used to place microinjection cannulas. Both groups were treated identically after surgery and run approximately in parallel. Our goal was to compare Fos plumes and behavioral effects of microinjections under identical conditions: namely, when a drug is likely to have maximum neurobiological/ behavioral effect, such when first microinjected, equivalent to day 1 of behavioral testing (below). This split-and-recombine design maximizes the impact of drug microinjection on Fos plumes as well as on behavior. It therefore avoids the danger of underestimating the volume of Fos plumes that might otherwise arise from measuring Fos plumes in rats used previously for behavioral microinjection tests (particularly if Fos plumes are reduced by accumulating damage produced by a previous series of microinjections). Our split-group procedure thus allowed within-subject comparison of drug effects on behavior while avoiding confounds attributable to microinjection repetition on Fos plume measurement. Recombination of data from both groups integrated behavioral and Fos data obtained under similar conditions to generate Fos plume maps of opioid microinjection effects on "liking" and "wanting" (see Figs. 4, 5).

For the behavioral test group, rats were implanted with two oral cannulas (bilateral, for taste reactivity testing) plus four intracranial cannulas (for microinjections): two microinjection cannulas bilaterally placed in the NAc and two cannulas bilaterally in the VP. Most NAc placements were centered in the hedonic hotspot of the medial shell (a $1 \mathrm{~mm}^{3}$ volume in a rostrodorsal subregion of medial shell that was shown previously to support both DAMGO-induced increases in hedonic reactions to sucrose reactions and increases in food intake). The NAc hedonic hotspot is contained in the rostral half of the NAc medial shell and slightly dorsal within it, just anterior to the caudal edge of the islands of Calleja but posterior to the caudal edge of the dorsal tenia tecta and the lateral septum and at or rostral to the level of the anterior commissure (Peciña and Berridge, 2005) (Fig. 1). Other NAc sites were staggered more widely throughout medial shell for site comparison (Peciña and Berridge, 2005). Most VP placements were centered in the hedonic hotspot in its posterior one-third (a $0.8 \mathrm{~mm}^{3}$ hotspot in which DAMGO similarly produces increases in both "liking" reactions and food intake) (Smith and Berridge, 2005). The VP hotspot is contained in the posterior one-third of ventral pallidum, just anterior to the rostral tip of the lateral hypothalamus and posterior to the caudal tip of the olfactory tubercule, level with the interventricular foramen (Smith and Berridge, 2005) (Fig. 1). On two test days, rats were given bilateral $\mu$-opioid agonist (DAMGO) microinjections in the NAc. On one of those days, at the same time, rats were also given bilateral microinjections of an opioid antagonist (naloxone) in the VP (Fig. 1). On the other NAc-DAMGO day, rats were given vehicle microinjections in the VP. On another $2 \mathrm{~d}$, the same rats received DAMGO bilaterally in the VP and either vehicle or naloxone bilaterally in the NAc. Vehicle was administered in both the NAc and VP on a fifth test day (double-vehicle control condition).

Thirty minutes after each microinjection combination, rats were tested for taste reactivity in a $1 \mathrm{~min}$ test and then immediately after were tested for food intake and eating behavior in a $1.5 \mathrm{~h}$ ad libitum test with familiar chow pellets (Fig. 1). To elicit "liking" reactions in behavioral taste reactivity tests, infusions of $1.5 \mathrm{ml}$ sucrose solution were made into rats' mouths via oral cannulas while affective orofacial reactions were video recorded.

For the Fos plume group, rats were similarly implanted with microinjection cannulas in NAc and VP and treated similarly after surgery. Local spread of drug-induced neural activation was assessed by measuring local Fos plumes caused by DAMGO or naloxone microinjection in separate rats, and their measured sizes were used to map reward functions in the NAc and VP (Fig. 2) (see Figs. 4, 5). In addition, we also measured distant Fos expression in the VP (and LH) after DAMGO or naloxone microin- 
jection in the NAc shell and similarly measured distant Fos expression in the NAc shell (and NAc core and LH) after microinjections in the VP.

Surgery: NAc and VP cannulas. Male Sprague Dawley rats were pretreated with $0.2 \mathrm{ml}$ of atropine sulfate, anesthetized with $80 \mathrm{mg} / \mathrm{kg}$ ketamine $\mathrm{HCl}$ and $10 \mathrm{mg} / \mathrm{kg}$ xylazine, and positioned in a stereotaxic apparatus (David Kopf Instruments, Tujunga, CA). Chronic stainless steel guide cannulas (23 gauge) were implanted $2.5 \mathrm{~mm}$ above target sites in the NAc and VP (Paxinos and Watson, 2005). Target sites in the NAc were distributed to cover the central dorsal hedonic hotspot in medial shell (Peciña and Berridge, 2005). Coordinates for the NAc shell were as follows: bilateral anteroposterior (AP), +1.1 to $+3.3 \mathrm{~mm}$; mediolateral $(\mathrm{ML}),+0.8$ to $+1.2 \mathrm{~mm}$; dorsoventral (DV), -6.8 to -8.1 $\mathrm{mm}$ below skull (incisor bar set at $8.3 \mathrm{~mm}$ above flat skull during NAc placements to avoid penetrating lateral ventricles). Sites in the VP were targeted to cover the hedonic hotspot in caudal VP (bilateral AP, -0.5 to $-1.2 \mathrm{~mm}$; $\mathrm{ML},+2.0$ to $3.2 \mathrm{~mm}$; DV, -7.6 to $-8.5 \mathrm{~mm}$; incisor bar set for flat skull) (Smith and Berridge, 2005). As far as possible, sites were kept bilaterally symmetrical within each rat. All four guide cannulas were anchored to the skull with four bone screws and acrylic cement, and stainless steel obturators were inserted in guide cannulas to prevent occlusion. Rats were allowed to recover for at least $7 \mathrm{~d}$ before behavioral testing.

Surgery: intraoral cannulas. In the same surgery, each rat was additionally implanted with bilateral oral cannulas [polyethylene (PE)-100 tubing] to permit oral infusions of sucrose solutions for taste reactivity testing. Oral cannulas enter the mouth in the upper cheek lateral to the first maxillary molar, travel beneath the zygomatic arch, and exit the dorsal head near the skull screws, in which they were anchored with acrylic cement (Grill and Norgren, 1978; Grill and Berridge, 1985). Oral cannulas did not disrupt normal eating.

Microinjections. Drugs were 0.05 $\mu \mathrm{g} / 0.2 \mu \mathrm{l}$ DAMGO and $10 \mu \mathrm{g} / 0.2 \mu \mathrm{l}$ naloxone (Sigma, St. Louis, MO). DAMGO dose was chosen based on previous results to produce maximum increases in sucrose positive hedonic reactions and food intake, and the naloxone dose was chosen to block intake (Kelley et al., 1996; Skoubis and Maidment, 2003; Peciña and Berridge, 2005; Smith and Berridge, 2005). Each drug was dissolved in $0.2 \mu \mathrm{l}$ of artificial CSF (ACSF) (Harvard Apparatus, Holliston, MA). Microinjections were made using a stainless steel injector cannula (29 gauge) that extended $2.5 \mathrm{~mm}$ beyond the ventral end of the guide cannulas, connected to PE-20 tubing and a syringe pump. Rats were gently handheld and infused at a rate of $0.30 \mu \mathrm{l} / \mathrm{min}$. Simultaneous infusions were first made for unilateral NAc and VP sites and followed by simultaneous contralateral infusions. Microinjector tips were held in place for an additional $1 \mathrm{~min}$ after each infusion to allow drug diffusion, and then obturators were reinserted and the animal was placed in the testing chamber. Animals were habituated to procedures for at least $3 \mathrm{~d}$ before testing and received a mock injection of vehicle on the final habituation day.

Each rat received five combinations of drug: (1) DAMGO in NAc plus vehicle in VP; (2) DAMGO in NAc plus naloxone in VP; (3) vehicle in NAc plus DAMGO in VP; (4) naloxone in NAc with DAMGO in VP; (5) vehicle in NAc plus vehicle in VP; or double-vehicle control (Fig. 1). The test order of drug combinations was balanced across rats, and no more than five microinjections were administered per rat to avoid accumulation of local damage or gliosis at the site that would interfere with drug effects.

Taste reactivity testing. The hedonic impact of tastes can be measured by behavioral taste reactivity patterns ("liking" reactions), which are homologous across rodent and primate species (Grill and Norgren, 1978; Grill and Berridge, 1985; Berridge, 2000; Steiner et al., 2001). We tested affective orofacial reactions of rats to a $1 \mathrm{ml}$ volume of sucrose solution infused into the mouth via oral cannula $30 \mathrm{~min}$ after simultaneous NAc and VP microinjection combinations of DAMGO, naloxone, or vehicle described above (Fig. 1). The $30 \mathrm{~min}$ time point was chosen because previous NAc and VP studies found maximal increases in hedonic reactions to sucrose at $\sim 30 \mathrm{~min}$ after DAMGO microinjections (Peciña and Berridge, 2005; Smith and Berridge, 2005). To infuse sucrose solution into the mouth, a $1 \mathrm{ml}$ syringe containing sucrose $(1.0 \%$; $0.029 \mathrm{M})$ was attached via hollow tubing (PE-50 connected to a PE-10 delivery nozzle) to a single oral cannula. In each taste reactivity test, a $1 \mathrm{ml}$ volume of sucrose was infused via syringe pump in 1 min duration. Orofacial taste reactivity responses were video recorded via close-up lens and an angled mirror placed underneath the transparent floor. To control for direct motor effects of drug microinjections on orofacial movements in the absence of taste stimuli, we also scored reactions in a $10 \mathrm{~s}$ baseline period immediately before each sucrose infusion.

Taste reactivity video scoring. Hedonic, aversive, and neutral taste reactivity patterns were later scored off-line in slow motion ( $1 / 30 \mathrm{~s}$ frame-byframe to $1 / 1$ oth actual speed) using established procedures developed to assess hedonic versus aversive taste valuation (Grill and Berridge, 1985; Berridge, 2000). Hedonic responses included rhythmic midline tongue protrusions, lateral tongue protrusions, and paw licks. Aversive responses included gapes, head shakes, face washes, forelimb flails, and chin rubs. Neutral responses included passive dripping of solution out of the mouth, ordinary grooming, and rhythmic mouth movements. Video analyses were conducted blind to the microinjection drug condition. For examples of taste reactivity, see supplemental video (available at www. jneurosci.org as supplemental material). 
A time-bin scoring procedure was used to ensure that taste reactivity components of different relative frequencies still contributed equally to the final affective hedonic/aversive totals (Berridge, 2000). Specifically, this ensured that shifts in frequent components (e.g., rhythmic tongue protrusions) did not swamp shifts in more rare but equally informative components (e.g., lateral tongue protrusions). For example, rhythmic mouth movements, passive dripping of solution, paw licking, and grooming reactions occur in long bouts and were thus scored in $5 \mathrm{~s}$ time bins ( $5 \mathrm{~s}$ equals one bout occurrence). Tongue protrusions and chin rubs, which occur in shorter bouts, were scored in $2 \mathrm{~s}$ time bins. The other behavioral components (lateral tongue protrusions, gapes, forelimb flails, and head shakes) typically occur in discrete events and were thus scored as single occurrences each time they occurred (e.g., one gape equals one occurrence). Individual rat totals were calculated for hedonic versus aversive categories by adding all response scores within an affective category for that rat. A hedonic "liking" reaction total was the sum of scores for lateral tongue protrusions, rhythmic tongue protrusions, and paw licks. An aversive "disliking" reaction total was the sum of gapes, head shakes, face washes, forelimb flails, and chin rubs.

Eating and food intake testing. Immediately after taste reactivity testing (time of $31 \mathrm{~min}$ after microinjection), rats were placed in a transparent tub cage containing cob bedding, preweighed chow pellets, and water (Fig. 1). To track the time course of eating stimulation, the duration of videotaped eating behavior was scored in $15 \mathrm{~min}$ bins. Cumulative food intake was also weighed after $1.5 \mathrm{~h}$ of ad libitum access to food $(2 \mathrm{~h}$ after microinjection), and rats were returned to their home cages. Intake was always tested after taste reactivity to ensure that satiety levels were equivalent for all rats (e.g., after ingesting a controlled $1 \mathrm{ml}$ amount of sucrose solution). If taste reactivity had been tested after food intake test, satiety alliesthesia would have suppressed "liking" reactions to sucrose in animals with high food intake. Thus, the order of testing kept the taste reactivity assessment uncontaminated but also kept satiety levels at the onset of the food intake test reasonably low and controlled.

Histology. For localization of cannulas used for behavioral testing, rats were deeply anesthetized with sodium pentobarbital at the end of the experiment, microinjected with ink $(0.2 \mu \mathrm{l})$ to mark the cannula tip, and transcardially perfused with buffered saline followed by $4 \%$ paraformaldehyde solution. Brains were removed, postfixed in $10 \%$ paraformaldehyde, cryoprotected with buffered $20 \%$ sucrose solution, and sectioned $(60 \mu \mathrm{m})$ in either coronal or horizontal planes, and, for a subgroup, alternating sections were either stained with cresyl violet or processed for leu-enkephalin immunochemistry. Most brains were sectioned coronally for initial mapping because of the greater detail in coronal mapping in available rat brain atlases. Microinjection location maps (see Figs. 4, 5) were constructed by identifying the spread of ink from the center of the microinjector tip placement on tissue sections and identifying threedimensional coordinates (Paxinos and Watson, 1998). The coordinates of identified points were then transposed into sagittal maps that better revealed the entire structures (and best illustrate functional gradients), and averaged Fos plume boundaries were plotted around each transposed point.

Leu-enkephalin immunohistochemistry. For cannulas in the VP, locations were confirmed based on leu-enkephalin staining of VP boundaries, which were visible because the VP contains a higher density of enkephalin-stained fibers and terminals than neighboring structures (Zahm et al., 1985; Zahm, 1989; Holt and Newman, 2004). After perfusions, brains were removed and placed in $4 \%$ paraformaldehyde for $2 \mathrm{~h}$ and then placed in phosphate-buffered 30\% sucrose overnight. The brains were sectioned in horizontal or coronal planes on a sliding microtome at $60 \mu \mathrm{m}$ and collected in staining wells containing $0.2 \mathrm{M}$ sodium phosphate buffer $(\mathrm{NaPb}), \mathrm{pH}$ 7.4. Sections were rinsed in $0.1 \mathrm{M}$ potassium PBS (KPBS), pH 7.2 (three times for $10 \mathrm{~min}$ ) and incubated for 1-2 $\mathrm{h}$ in normal goat serum solution containing KPBS and 10\% Triton $\mathrm{X}-100$. Sections were again rinsed with KPBS and incubated for $24 \mathrm{~h}$ in anti-rat leu-enkephalin antibody (rabbit polyclonal; Pennsylvania Laboratories, Belmont, CA) solution at a concentration of 1:5000 containing KPBS and 10\% Triton X-100. After a KPBS rinse, the sections were then exposed to a goat anti-rabbit, biotinylated secondary IgG (Santa Cruz Biochemicals, Santa Cruz, CA) diluted 1:200 and then to the avidin- biotin-peroxidase complex for $1 \mathrm{~h}$. To visualize leu-enkephalin, we used a nickel diaminobenzidine (nickel-DAB) glucose oxidase reaction. Sections were washed, mounted, dried, and visualized as described below for Fos immunocytochemistry.

Fos-like protein immunohistochemistry. Fos plumes revealing the anatomical spread of immediate early gene activation caused by drug microinjections were assessed using a separate group of rats. Distant Fos effects caused by microinjections were also examined in the same rats to determine if opioids in one hotspot were recruiting cell activity in the other hotspot. Rats in the Fos group received DAMGO, naloxone, or vehicle microinjection combinations in the NAc and VP under conditions identical to those the behavioral group received on their first day of testing. Cannulas placements in the Fos group coincided with placements in the behavioral test group.

Seventy-five min after drug microinjection, rats were deeply anesthetized with sodium pentobarbital before transcardial perfusion (Herrera and Robertson, 1996). Brains were removed and placed in $4 \%$ formaldehyde for $2 \mathrm{~h}$, placed in $30 \%$ sucrose overnight, and then sectioned at 60 $\mu \mathrm{m}$ and stored in $0.2 \mathrm{M} \mathrm{NaPb}$ ( $\mathrm{pH}$ 7.4). To visualize Fos-like immunoreactivity, we used the avidin-biotin procedure (Hsu et al., 1981). Brain sections were immersed in blocking solution ( $3 \%$ normal goal serum and $0.3 \%$ Triton X-100 in TPBS) for $1 \mathrm{~h}$ and then incubated at room temperature for $24 \mathrm{~h}$ with a rabbit polyclonal antiserum directed against the $\mathrm{N}$-terminal region of the Fos gene (Sigma, St Louis; dilution of 1:5000 in triton phosphate buffered saline, $1 \%$ normal goat serum and $0.3 \%$ Triton $\mathrm{X}-100)$. To reduce background staining the antiserum was preabsorbed with acetone-dried rat liver powder overnight at $4^{\circ} \mathrm{C}$. After the primary antibody incubation, tissue was exposed to goat anti-rabbit, biotinylated secondary IgG (Santa Cruz Biochemicals, CA; diluted 1:200) and then to avidin-biotin-peroxidase complex for $1 \mathrm{~h}$ at room temperature. A nickel diaminobenzidine glucose oxidase reaction was used to visualize Fos-like immunoreactive cells. Finally, sections were washed in Tris buffer, mounted from PBS, air dried, dehydrated in alcohol, cleared in xylene, and coverslipped. Fos-like immunoreactivity was visualized using a Leica (Nussloch, Germany) microscope coupled to a SPOT RT slider (Diagnostic Instruments, Sterling Heights, MI) using SPOT software (SPOT version 3.3).

Fos plume of drug functional spread. Measured radii of Fos plumes were used to calculate the volumes of local drug activation spheres and to map functional consequences onto the cannula sites (at equivalent locations) used for behavioral tests (Peciña and Berridge, 2000, 2005; Smith and Berridge, 2005) (Fig. 2). Following previous methods for Fos plume analyses (Peciña and Berridge, 2000, 2005; Smith and Berridge, 2005), Foslabeled cells were counted individually within blocks $(125 \times 125 \mu \mathrm{m})$ on tissue surface with 5-40× magnification at point locations spaced at 125 $\mu \mathrm{m}$ intervals along each of seven radial arms emanating from the center of the microinjection site $\left(45,90,135,180,225,270\right.$, and $\left.315^{\circ}\right)$. For microinjection sites, Fos densities were measured (1) in normal tissue of brains without a microinjection cannula to assess normal baseline expression, (2) around the site of vehicle microinjections to assess cannula track and vehicle-induced Fos baseline expression, and (3) around the local site of drug microinjections to assess drug-induced changes in Fos caused by DAMGO or naloxone. Fos plumes surrounding drug microinjections were mapped into zones of intense versus moderate Fos levels. Intense and moderate zones were identified in two ways: (1) as absolute increases over normal levels [elevation by 10 times $(10 \times)$ (intense) or five times $(5 \times)$ (moderate) normal tissue counts sampled in the absence of any cannula track], and (2) as vehicle-relative increases caused by drug [elevation by $5 \times$ or two times $(2 \times)$ over vehicle microinjection-induced levels at equivalent point locations around drug vs vehicle microinjection tracks] (Fig. 2).

Mapping drug functional effect with Fos plumes. Cannulas placements for each behavioral-tested rat were plotted onto a sagittal brain view using hexagon symbols. The size of each symbol was determined by the average radius of Fos plumes caused by that drug at equivalent sites measured in the Fos-tested group. The color of each symbol was determined by the intensity of behavioral changes in "liking" or food intake caused by drug microinjection in the behavior-tested rat at that site. Thus, we plotted the "liking" and "wanting" effects of opioid agonist and 
antagonist microinjections in plume-based maps that incorporated Fos data on where the drug microinjections acted and where they stopped acting (see Figs. 4, 5).

Fos maps of activation in distant target sites. Opioid drug microinjections can induce Fos expression in distant brain structures (Zhang and Kelley, 2000). To assess whether NAc and VP hotspots interact neurobiologically with each other, we examined immunoreactivity to Fos expression induced at a distance in the VP after DAMGO or naloxone microinjections in the NAc shell in the same animals used for plume analyses (Fig. 3). We similarly examined Fos in the NAc shell after microinjections in the VP. In addition, we sampled Fos in the LH because it is another important output stage for NAc and VP signals (Heimer et al., 1991; Berthoud, 2002; Will et al., 2003) and in the NAc core, in addition to shell, because it is implicated in NAc opioid stimulation of food intake (Kelley et al., 2002). To ensure that Fos expression in the distant structure would not be affected by its own surgical invasion, rats used for distant Fos mapping were implanted with cannulas only in the microinjection target (VP or NAc) and not in the distant structures that were sampled in that condition (NAc, VP, and LH).

To assess Fos expression in structure distant from the microinjection site, we counted Fos densities in each structure at three coronal sections (Bontempi and Sharp, 1997; Zhang and Kelley, 2000; Levine and Billington, 2004; Stratford, 2005), at anteroposterior levels spanning the medial NAc shell or core, and the VP (Paxinos and Watson, 1998, 2005). The VP was examined after NAc shell microinjection, and the NAc shell was examined after VP microinjection (Fig. 3). To measure Fos in distant structures at $50 \times$ magnification, a $0.25 \mathrm{~mm}^{2}$ grid was placed at six positions within the structure (dorsal and ventral positions in each of the three rostrocaudal levels of VP and one level of rostral LH). Fos-like immunoreactive neurons within each position were tallied (Fig. 3).

These Fos counts were verified for $>75 \%$ of sections using Scion (Frederick, MD) Image software. For Scion Image analysis, a $1 \mathrm{~mm}^{2}$ box was placed in the center of a structure. This box was then isolated and imported into Scion Image software. Thresholds were set to be consistent with the subarea of the structure. The minimum/maximum point sampling criteria were 3 and 10, respectively. For the caudal VP, which is smaller than $1 \mathrm{~mm}^{2}$, a $0.25 \mathrm{~mm}^{2}$ Scion Image sampling box was used, and Fos counts within this box were quadrupled to normalize measurements.

Statistical analysis. The effect of the five NAc/VP combinations of DAMGO, naloxone, or vehicle on the number of hedonic responses to sucrose were analyzed with a one-way ANOVA, followed by Tukey'scorrected post hoc comparisons for drug interaction. A separate one-way ANOVA and post hoc comparisons were conducted for drug effects on food intake and eating duration, and observed power was calculated for each ANOVA. Fos immunoreactivity counts in either the VP or NAc, and rostrocaudal site variation within each structure, were examined with a one-way ANOVA (drug).

\section{Results}

We measured (1) local Fos plumes produced by opioid agonist and antagonist microinjections (to assess where drugs acted and where they stopped acting), (2) distant Fos effects of opioid microinjections (to assess neurobiological interactions between hotspots in different brain structures), and both (3) "liking" (positive hedonic reactions to sucrose) and (4) "wanting" (food intake) behavioral consequences of equivalent microinjections (to map reward functions and assess functional properties of limbic circuits).

To facilitate recombination of Fos plume data and behavioral data, equivalent microinjection sites were matched across groups. For example, 95\% of NAc-VP hotspot sites in the behavioral group corresponded to within inner Fos plumes for DAMGO sites in the Fos group, and 100\% of behavioral group sites were contained at least within the moderate-mild outer Fos plumes of Fos group sites. This accounted for most placements because most sites for both groups were within the identified hotspots of NAc or VP ( $88 \%$ for the Fos group; $68 \%$ for the behavioral group). For the remaining microinjection cannulas that were located outside the anatomical boundaries of an NAc or VP hotspot, $100 \%$ of behavioral group sites still fell within the outer DAMGO Fos plume zone of mild elevation, and no behavioral group site was farther than $0.8 \mathrm{~mm}$ from the center of a mapped Fos plume. This close correspondence between sites of the behavioral and Fos groups gave grounds for confidence that Fos plume and behavioral data could be recombined into integrated Fos plume maps of opioid microinjection effects on behavioral "liking" and "wanting" functions.

\section{Microinjection Fos plumes: local impact spread of DAMGO and naloxone}

The size and intensity of Fos plumes at the local site of microinjection revealed the degree and anatomical spread of local druginduced immediate early gene transcription of c-fos into Fos protein directly surrounding a microinjection cannula. DAMGO caused localized plumes of elevated Fos immunoreactivity at the site of microinjection in the NAc or VP, consistent with previous reports (Peciña and Berridge, 2005; Smith and Berridge, 2005) 
(Fig. 2). To establish baselines, we separately measured Fos in virgin normal tissue (unoperated brain structures is equivalent to normal baseline) and surrounding the site of ACSF vehicle microinjections (vehicle baseline; this was usually slightly higher than virgin normal baseline because vehicle microinjections, even without drug content, produced a small plume of Fos elevation perhaps attributable to ACSF chemical stimulation or pressure). Normal Fos baseline was low, especially in the VP, and just slightly higher in the NAc (VP, $0.94 \pm 0.16$, mean \pm SEM; Fos counts per sampled $125 \times 125 \mu \mathrm{m}$ tissue area; NAc, $2.57 \pm 0.18$; $\left.F_{(1,69)}=45.42 ; p<0.001\right)$. Vehicle baselines around cannulas were slightly higher than normal baselines (NAc, $3.4 \pm 0.45$ $\mathrm{mm}^{3}$; VP, $5.4 \pm 1.05 \mathrm{~mm}^{3}$; within $0.31 \mathrm{~mm}^{3}$ radius each surrounding microinjector; $\sim 0.12 \mathrm{~mm}^{3}$ sphere of tissue volume; $\left.F_{(1,12)}=5.24 ; p<0.05\right)$.

Fos changes caused by drugs were computed relative to both normal baseline level and vehicle baseline level for the same structure. Zones of intense DAMGO-evoked Fos elevation were defined as $>10 \times$ increase over normal or vehicle baselines. Zones of moderate elevation were defined as $>5 \times$ increases, and low elevation was defined as $>2 \times$ increases. For each intensity level (high, medium, and low Fos elevation) plume sizes were averaged across normal Fos (virgin unoperated tissue) and vehicle (ACSF microinjection) comparison standards to compute a mean plume size for that intensity level and were used to plot in functional maps (Fig. 2).

DAMGO causes Fos plumes in NAc and VP (Fig. 2)

DAMGO microinjections in the NAc caused inner plumes of intense Fos elevation $(>10 \times)$ that were $\sim 0.02 \mathrm{~mm}^{3}$ in volume (calculated from measured radius assuming approximately spherical three-dimensional shape of plume), surrounded by moderate $(>5 \times)$ and mild elevation zones $(>2 \times)$ of up to $\sim 2.95$ $\mathrm{mm}^{3}$ in spherical volume (Fig. 2). In the NAc, the radius of intense plumes was $0.17 \pm 0.04 \mathrm{~mm}$ (mean \pm SEM) defined in terms of elevation over normal baseline and $0.41 \pm 0.05 \mathrm{~mm}$ when defined in terms of vehicle baseline. Moderate $(>5 \times)$ plumes were larger $(0.51 \pm 0.10 \mathrm{~mm}$ radius $)$, and mild $(>2 \times)$ plumes were largest of all $(0.79 \pm 0.17 \mathrm{~mm}$, or $0.89 \pm 0.21 \mathrm{~mm}$ defined by vehicle baseline).

In the VP, intense Fos plumes were slightly larger in spherical volume $\left(0.23 \mathrm{~mm}^{3}\right)$ than in NAc when defined in terms of elevation over normal tissue, perhaps as a consequence of starting from a lower normal baseline in the VP than in the NAc (intense $10 \times \mathrm{VP}$ plume, $0.38 \pm 0.07 \mathrm{~mm}$ radius; $F_{(1,5)}=8.66 ; p<0.05$ compared with NAc), but the size of $>5 \times$ and $>2 \times$ outer plumes did not differ between structures (low $2 \times$ VP plume, 3.16 $\mathrm{mm}^{3}$ in spherical volume, $0.91 \pm 0.11 \mathrm{~mm}$ radius; moderate $5 \times$ VP plume, $0.65 \pm 0.07 \mathrm{~mm} ; F_{(1,17)}=0.97$; NS compared with NAc) (Fig. 2). Calculations for vehicle-relative plumes in the VP were similar to NAc vehicle plumes $(5 \times, 0.63 \pm 0.16 \mathrm{~mm} ; 2 \times$, $0.56 \pm 0.30 \mathrm{~mm})$.

Naloxone anti-plumes suppress local Fos expression below baseline (Fig. 2)

In contrast to DAMGO-induced plumes of Fos elevation, naloxone actually suppressed local Fos immunoreactivity below baseline levels, producing "anti-plumes" of Fos inhibition (Fig. 2). Thus, opioid effects on local Fos were bidirectional. Anti-plumes were useful in localizing naloxone effects, and, to quantify antiplumes, we measured zones of moderate Fos suppression [more than $-10 \%$ reduction ( $<90 \%$ of baselines)] and of intense Fos suppression [more than $-25 \%(<75 \%$ baselines $)$ ].

Naloxone anti-plumes were large, totaling $8.78 \mathrm{~mm}^{3}$ in spher- ical volume for moderate anti-plumes to $11.99 \mathrm{~mm}^{3}$ for surrounding intense anti-plumes $(0.98-1.32 \mathrm{~mm}$ radius in NAc and $1.28-1.42 \mathrm{~mm}$ in VP). Suppression actually became more intense moving from inner to outer layers of the naloxone anti-plume sphere. That was in part because naloxone actually induced a small excitatory center inside anti-plumes (NAc: $2 \times$ normal, $0.14 \pm 0.80 \mathrm{~mm} ; 2 \times$ vehicle, $0.11 \pm 0.03 \mathrm{~mm}$ radius; $\mathrm{VP}: 2 \times$ normal, $0.58 \pm 0.10 \mathrm{~mm} ; 2 \times$ vehicle, $0.33 \pm 0.03 \mathrm{~mm}$ ). This excitatory center may account for why Fos elevation has been reported after local naltrexone infusion (Li et al., 2006). In our hands, the naloxone excitatory plume center was intense enough to overwhelm surrounding anti-plume inhibitions if counts from all zones were averaged together (145\% increase in Fos expression overall). When inner center and outer surround zones were analyzed separately, however, it seemed clear that naloxone microinjection caused a small center sphere of mild Fos elevation surrounded by robust anti-plumes that were 10-100 times larger ( $>1.0 \mathrm{~mm}$ radius; $10 \mathrm{~mm}^{3}$ volume). Fos suppression grew in suppression intensity toward the outer borders before rapidly returning to baseline levels (Fig. 2).

\section{Distant Fos expression in structures away from the microinjection site}

Opioid hotspots in the NAc and VP interacted in a reciprocal and bivalent manner, suggesting that a close link connects their neurobiological function. Opioid DAMGO microinjections in one hotspot recruited distant Fos elevation in the other hotspot (in addition to causing a local Fos plume). Conversely, naloxone microinjections in one hotspot recruited suppression of distant Fos in the other hotspot (in addition to causing local anti-plumes of Fos suppression).

NAc microinjections affect Fos expression in VP and LH (Fig. 3) Microinjection of DAMGO in the NAc shell caused Fos elevation in distant targets of VP and LH (two-way ANOVA, drug $\times$ target; $F_{(1,44)}=11.48, p<0.01$ for drug; $F_{(1,44)}=0.23$, NS for interaction) (Fig. 3). The highest Fos VP elevation was in the anatomically defined hedonic hotspot region in the posterior VP described by us previously (Smith and Berridge, 2005) compared with other anterior/central subregions (ANOVA; $F_{(1,60)}=6.49$; $p<0.05)$. NAc-DAMGO elevated Fos $68 \%$ in the VP over normal tissue levels (mean \pm SEM counts; $\mathrm{VP}_{\mathrm{NAc}-\mathrm{DAMGO}}, 23.87 \pm$ 2.77; $\left.\mathrm{VP}_{\mathrm{NAc}-\text { vehicle }}, 14.20 \pm 2.08 ; F_{(1,24)}=6.42 ; p<0.05\right)$. In the anterior $\mathrm{LH}$, Fos was elevated by $50 \%\left(\mathrm{LH}_{\mathrm{NAc}-\mathrm{DAMGO}}, 29.36 \pm\right.$ 4.48; $\left.\mathrm{LH}_{\mathrm{NAc}-\text { vehicle }}, 16.50 \pm 2.67 ; F_{(1,18)}=4.99 ; p<0.05\right)$.

Microinjections of naloxone in NAc shell caused an opposite suppression of Fos in VP and LH (two-way ANOVA, drug $X$ target; $F_{(1,35)}=6.61, p<0.05$ for drug; $F_{(1,35)}=1.29$, NS for interaction) (Fig. 3). Naloxone in the NAc moderately suppressed Fos by $22 \%$ throughout the $\mathrm{VP}\left(\mathrm{VP}_{\mathrm{NAc}-\text { naloxone }}, 11.00 \pm\right.$ 2.43; $\left.\mathrm{VP}_{\mathrm{NAc}-\text { vehicle, }} 14.20 \pm 2.08\right)$ and did not vary between $\mathrm{VP}$ subregions $\left(F_{(1,35)}=2.40 ; \mathrm{NS}\right)$. NAc naloxone suppressed Fos in $\mathrm{LH}$ by $\sim 50 \%\left(\mathrm{LH}_{\mathrm{NAc}-\text { naloxone}}, 8.25 \pm 1.46, t_{(10)}=3.77\right.$; $\mathrm{LH}_{\mathrm{NAc}-\mathrm{vehicle}}, 16.50 \pm 2.67, F_{(1,15)}=7.34 ; p<0.05$ ) (Fig. 3). Distant suppression persisted even outside the radius of local Fos anti-plumes caused by naloxone microinjections in rostral NAc, indicating that it was not attributable to simple diffusion of naloxone to the distant site.

VP microinjections affect Fos in NAc shell but not core or LH (Fig. 3)

Similarly, DAMGO microinjections in the posterior VP robustly elevated Fos in the NAc shell hotspot (two-way ANOVA, drug $X$ target; $F_{(1,38)}=19.61, p<0.001$ for drug; $F_{(1,37)}=18.25, p<$ 
0.001 for interaction) (Fig. 3). VP-DAMGO nearly tripled distant Fos levels in the NAc medial shell (NAc-Shell ${ }_{\mathrm{VP}-D A M G O}, 77.89 \pm$ 10.83; NAc-Shell ${ }_{\mathrm{VP}-\text { vehicle }}, 28.63 \pm 2.44 ; F_{(1,19)}=23.75 ; p<$ $0.001)$, especially in the dorsal half of shell that contains the hedonic hotspot (dorsal vs ventral, $F_{(1,17)}=8.74, p<0.01$; medial/ lateral and anterior/posterior elevations did not differ: medial/ lateral, $F_{(1,17)}=0.39$, NS; anterior/posterior, $F_{(2,35)}=1.67, \mathrm{NS}$ ) (Peciña and Berridge, 2005). In contrast to shell, NAc core Fos was not elevated by DAMGO microinjections in the VP (NAcCore $_{\text {VP-naloxone, }} 14.11 \pm 2.96 ; F_{(1,17)}=0.01$, NS), nor was LH Fos affected by VP-DAMGO $\left(F_{(2,5)}=0.73\right.$; NS $)$.

Conversely, naloxone in VP suppressed NAc shell Fos 33\% below normal (NAc-Shell ${ }_{\mathrm{VP}-\text { naloxone, }} 19.11 \pm 3.38$; NAcShell $_{\text {VP-vehicle, }} 28.63 \pm 2.44 ; F_{(1,19)}=5.47 ; p<0.05$ ) (Fig. 3), especially in rostral and caudal tips of NAc (vs central shell, $F_{(2,35)}=10.66, p<0.001 ;$ medial/lateral and dorsal/ventral subregions did not differ). NAc core Fos was not suppressed by naloxone microinjection in the VP (NAc-Core ${ }_{\mathrm{VP}-\mathrm{DAMGO}}, 15.44 \pm$ 2.94; NAc-Core $\left.{ }_{\mathrm{VP} \text {-vehicle, }} 14.56 \pm 2.77 ; \mathrm{F}_{1,17}=0.05 ; \mathrm{NS}\right)$, nor was LH Fos suppressed $\left(F_{(2,5)}=0.73\right.$; NS). This pattern again suggests that distant suppression effects reported above were not attributable simply to diffusion of naloxone from the injection site.

Functional connectivity was therefore reciprocal between opioid hotspots in the NAc medial shell and VP (and, although not limited to the hotspots, appeared focused between them). However, VP opioid stimulation caused an increase in NAc Fos that was more than quadruple the magnitude of the reciprocal increase in VP Fos caused by NAc-DAMGO [NAc (after VPDAMGO), 272\%; VP (after NAc-DAMGO), 68\%; $F_{(1,23)}=$ 35.88; $p<0.001]$.

\section{Naloxone suppression of DAMGO plumes}

A separate question from whether microinjections in one hotspot can act at a distance to modulate Fos in another structure is whether simultaneous naloxone in either hotspot can modulate the local Fos plume normally produced by DAMGO microinjection in the other hotspot. This was also assessed, and we found that simultaneous microinjection of naloxone in VP reduced by $43 \%$ the size of DAMGO plumes produced in NAc by local DAMGO in the NAc $\left(0.51 \pm 0.24 \mathrm{~mm}^{3}\right)$ and abolished the intense $10 \times$ elevation zone of DAMGO plumes in NAc.

Conversely, simultaneous microinjection of naloxone in NAc reduced the size of VP-DAMGO plumes by $32 \%$ (to $0.62 \pm 0.17$ $\mathrm{mm}^{3}$ ), and the intense plume zone in the VP was suppressed by $\sim 50 \%\left(10 \times\right.$ normal, $\left.0.13 \pm 0.02 \mathrm{~mm}^{3}\right)$. Thus, naloxone in one hotspot feeds back to suppress the Fos plume normally produced around a DAMGO microinjection in the other hotspot.

\section{DAMGO stimulates sucrose "liking" reactions and food intake in NAc and VP}

\section{"Liking" is increased by NAc-DAMGO alone (vehicle in VP) or VP-DAMGO alone (vehicle in NAc) (see Fig. 4)}

Infusions of sucrose solution into the mouth elicited primarily positive hedonic reactions (e.g., lateral and rhythmic tongue protrusions and paw licks) and few or no negative aversive reactions (e.g., gapes). Microinjections of DAMGO into either the NAc or VP robustly enhanced the number of positive hedonic reactions up to $150 \%$ above double-vehicle baseline levels ( $\mathrm{NAc}_{\text {DAMGO}} /$ $\mathrm{VP}_{\text {vehicle }}, 137 \%$; $\mathrm{NAc}_{\text {vehicle }} / \mathrm{VP}_{\mathrm{DAMGO}}, 147 \%$; $\mathrm{NAc}_{\text {vehicle }} / \mathrm{VP}_{\text {vehicle, }}$, 100\%) (Fig. 4).

In the NAc, DAMGO microinjection increased the total number of positive hedonic reactions elicited by sucrose to $29.0 \pm$ 2.21 (mean \pm SEM) from double-vehicle levels of $21.19 \pm 2.20$
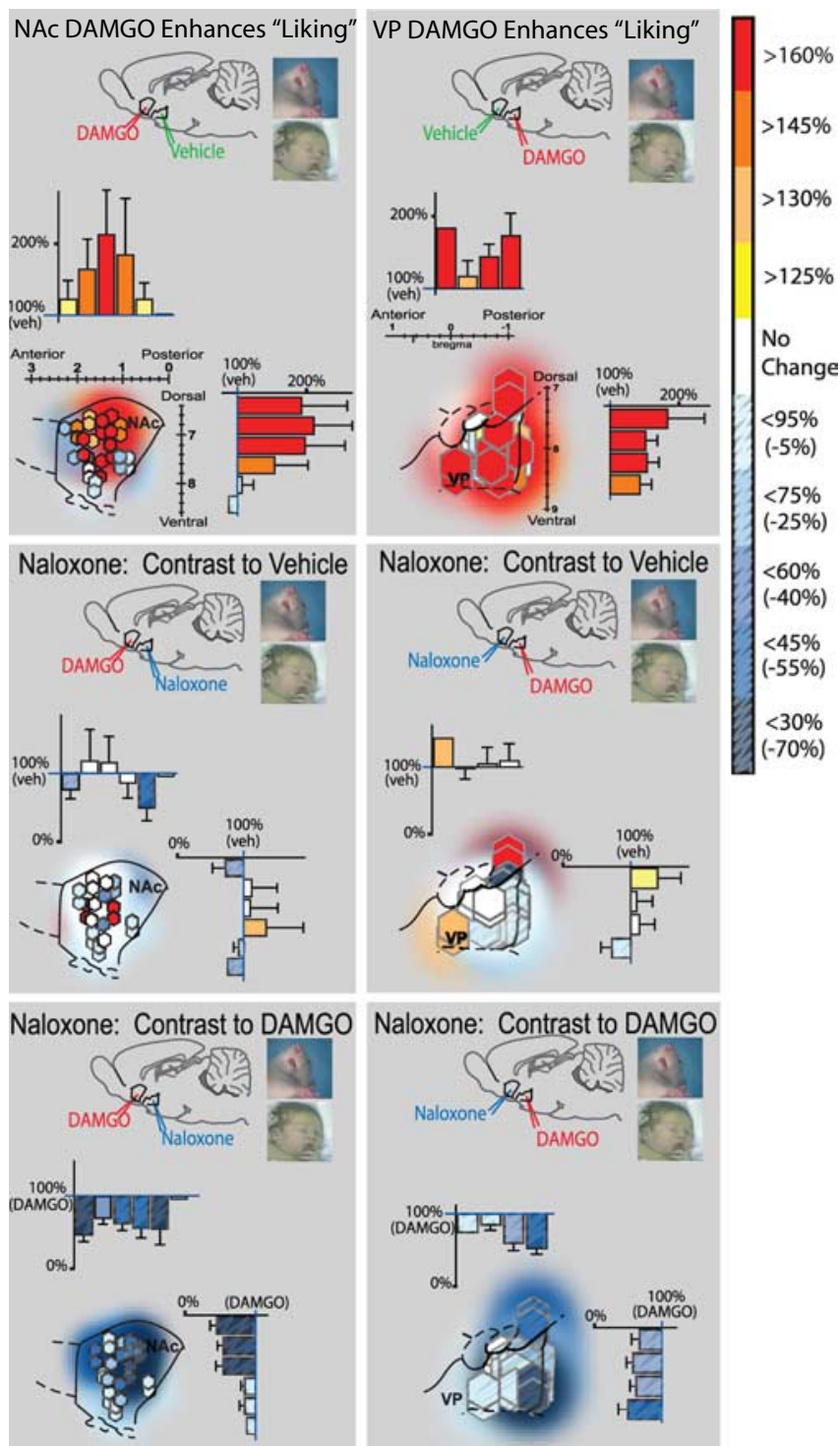

Figure 4. Fos plume map of hedonic "liking" effects of opioid activation (DAMGO) and block ade (naloxone). Sagittal views show inner Fos plumes as hexagons and outer plumes as surrounding shading (each unilateral site mapped separately is 2 symbols per rat). Symbol colors show percentage increase (yellow-red) or suppression (blue, stippling) of "liking" reactions elicited by sucrose after each DAMGO/naloxone combination [compared with either vehicle levels (top and middle) or "liking" enhancement after DAMGO alone (bottom)]. Bars along rostrocaudal and dorsoventral levels show intensity of drug effects within each 0.4-mm-wide level (mean \pm SEM percentage of vehicle levels; a plume contributes to more than 1 bar if it straddles multiple levels). Left column shows "liking" effects of NAc-DAMGO and VP-naloxone combinations. DAMGO in NAc enhanced sucrose "liking" over vehicle levels (top left; contrast for DAMGO vs double-vehicle control). Addition of VP-naloxone to NAc-DAMGO blocks NAcDAMGO enhancement over vehicle control levels (left middle; contrast to double-vehicle control). Addition of VP naloxone to NAc-DAMG0 therefore reduced "liking" reactions to below levels produced by NAC-DAMGO alone (left bottom; contrast to DAMGO alone). Right column shows "liking" effects of VP-DAMGO and NAc-naloxone combinations. VP-DAMGO alone (NAc-vehicle) enhanced "liking" reactions to sucrose taste over double-vehicle levels (top right; contrast to double vehicle). Adding naloxone to NAc blocked VP-DAMG0 ability to enhance "liking" reactions over vehicle (middle right; contrast to double vehicle) and therefore reduced "liking" to lower levels than after VP-DAMG0 alone (bottom right; contrast to DAMG0 alone). Sagittal structure outlines are modified from Paxinos and Watson (1998).

$\left(F_{(1,30)}=6.26 ; p<0.05\right.$; observed power, $0.68 ; \mathrm{NAc}_{\text {vehicle }} /$ $\left.\mathrm{VP}_{\text {vehicle }}, 100 \%\right)$ (Fig. 4). The highest increases in hedonic reactions were produced by DAMGO microinjection at sites that fell inside the anatomical hedonic hotspot previously identified by an 
earlier hedonic mapping study (a $1 \mathrm{~mm}^{3}$ volume in located in the dorsal and anterior-central quadrant of medial shell) (Peciña and Berridge, 2005). Within that NAc hotspot, DAMGO more than doubled "liking" reactions to sucrose (224\% above vehicle levels). NAc hotspot DAMGO microinjections produced greater enhancement of positive hedonic reactions to sucrose than equivalent microinjections in other shell locations outside the hotspot (which averaged a "liking" increase of only $110 \%$ above vehicle; $\left.F_{(1,14)}=4.58 ; p=0.05\right)$. Furthermore, DAMGO in a more posterior cold spot in the caudal half of medial shell sometimes even suppressed positive reactions (averaging $-15 \%$ below vehicle levels), again consistent with the previous study (Peciña and Berridge, 2005). Even DAMGO placements outside of the hotspot that did elevate "liking" reactions may have done so in part by impinging on the hotspot with a part of their Fos plumes. Of the two rats with enhancement sites centered outside the NAc hotspot, the moderate Fos plume zone of at least one cannula of both rats invaded the anatomical hotspot (as did both cannulas of one of the rats), and $100 \%$ of plumes invaded with at least their low elevation zone. Such observations raise the possibility that hedonic enhancement effects of virtually all effective NAc sites may have been attributable to opioid activation within the hotspot (Fig. 4).

The particular component reaction most significantly enhanced by NAc-DAMGO was rhythmic tongue protrusion elicited by sucrose $(p<0.05)$. NAc-DAMGO reciprocally decreased the category of more neutral, or less hedonically weighted, oral responses, such as rhythmic mouth movements, which can compete for expression with strongly hedonic reactions during a sucrose infusion $\left(F_{(1,30)}=10.23 ; p<0.01\right)$. Aversive reactions were not affected by NAc-DAMGO microinjection and remained always near zero as expected for palatable sucrose $\left(F_{(1,30)}=0.55\right.$; NS). Thus, NAc-DAMGO selectively potentiated hedonic reaction patterns only and did not change aversive reactions to sucrose.

VP microinjection of DAMGO in the posterior VP hedonic hotspot (combined with vehicle microinjection in the NAc) similarly increased positive hedonic reactions to sucrose to nearly $150 \%$ above vehicle $\left(\mathrm{NAc}_{\mathrm{vehicle}} / \mathrm{VP}_{\mathrm{DAMGO}}, 147 \% ; \mathrm{NAc}_{\mathrm{vehicle}} /\right.$ $\mathrm{VP}_{\text {vehicle }}, 100 \%$; raw totals, $31.07 \pm 2.35 ; \mathrm{NAc}_{\text {vehicle }} / \mathrm{VP}_{\text {vehicle }}$, $21.19 \pm 2.20 ; F_{(1,29)}=9.43 ; p<0.01$; observed power, 0.84 ) (Fig. 4). All but one of the DAMGO placements in VP that enhanced hedonic reactions was contained inside the caudal VP hotspot. Even the outlier placement still invaded the caudal VP hotspot with at least its outer Fos plume. Thus, similar to the NAc, it appeared possible that virtually all effective sites in VP may have exerted their hedonic enhancement effects via opioid activation of the anatomically defined hotspot in posterior VP.

Again, the particular component of positive hedonic reactions most enhanced by DAMGO was rhythmic tongue protrusions $(p<0.05)$. DAMGO in the VP hotspot similarly caused a reduction in relatively neutral reactions (e.g., rhythmic mouth movements $)\left(F_{(1,29)}=11.20 ; p<0.01\right)$ and did not raise or lower the near-zero levels of aversive taste reactivity elicited by sucrose $\left(F_{(1,29)}=0.30\right.$; NS $)$.

No motor effects of opioid microinjections on orofacial movements in the absence of taste

Direct motor effects of microinjections on movements were assessed in a baseline $10 \mathrm{~s}$ period before each sucrose infusion in every taste reactivity test. In the absence of sucrose taste, DAMGO microinjections did not elicit hedonic movements $\left(F_{(4,92)}=1.66\right.$; NS $)$, aversive movements $\left(F_{(4,92)}=2.23\right.$; NS $)$, or
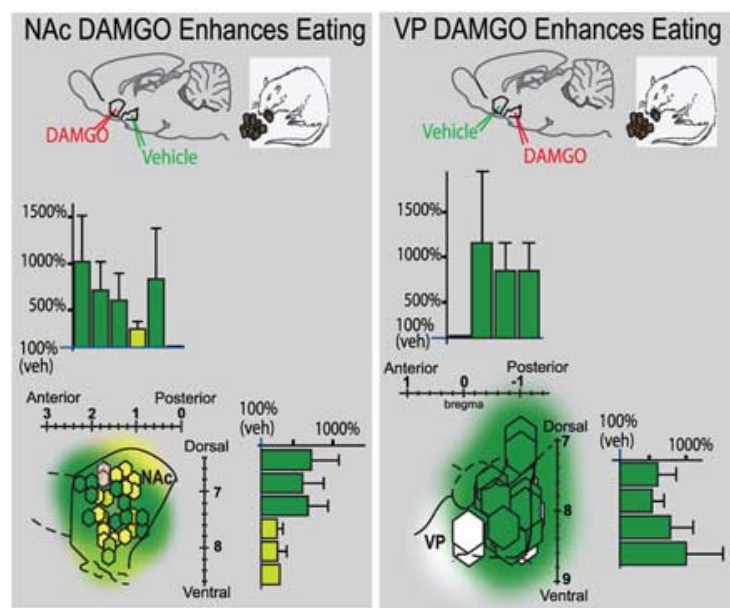

$>350 \%$

Naloxone: Contrast to Vehicle
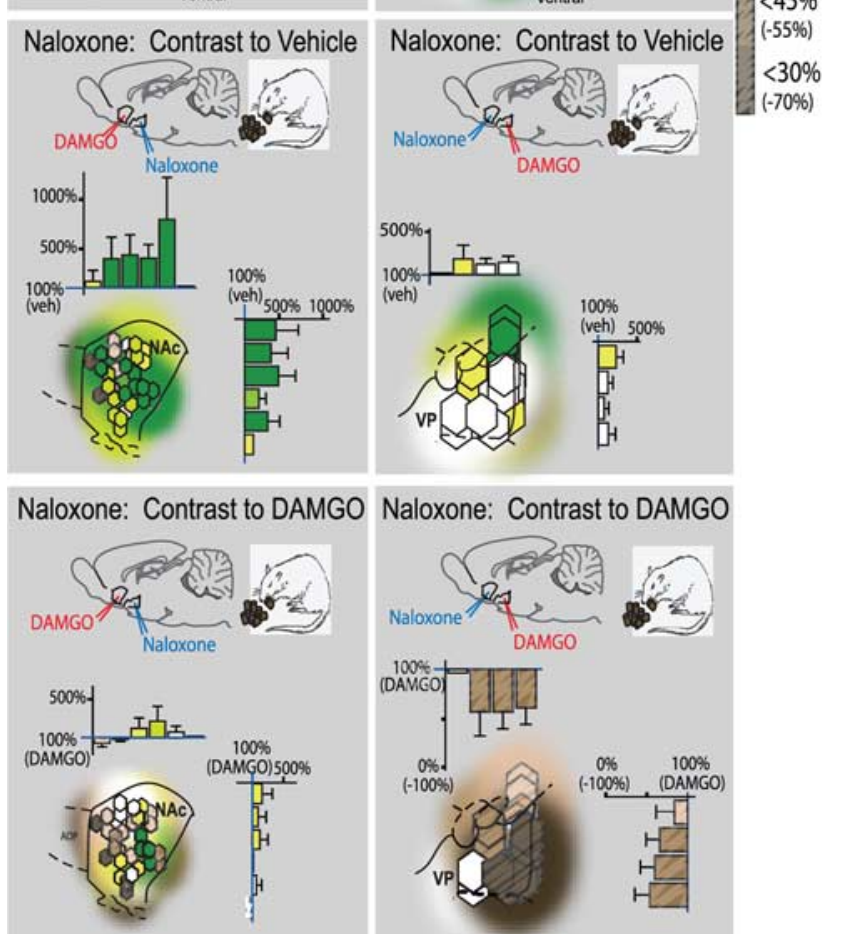

Figure 5. Fos plume map of eating/intake effects of opioid activation (DAMGO) and blockade (naloxone). Organization is similar to Figure 4. Colors denote increase (green) or decrease (brown, stippling) in food intake caused by drug combinations. NAc-DAMGO stimulated eating and food intake when combined with VP-vehicle (top left; contrast to double vehicle) and even when combined with VP-naloxone (middle left; contrast to double vehicle). Adding naloxone in VP to NAC-DAMGO therefore failed to reduce intake much below levels after NAC-DAMGO alone (bottom left; contrast to DAMGO alone). However, although VP-DAMGO equally enhanced food intake (top right; contrast to double vehicle), adding NAc-naloxone almost completely blocked the intake increase normally caused by DAMGO in VP (middle right; contrast to double vehicle) and therefore reduced intake after the combination to below the high levels produced by VP-DAMGO alone (bottom right; contrast to DAMG0 alone).

neutral movements $\left(F_{(4,92)}=0.75 ; \mathrm{NS}\right)$. There was also no effect on general grooming behavior $\left(F_{(4,92)}=1.94\right.$; NS). Thus, DAMGO microinjections specifically enhanced positive hedonic reactions elicited by sucrose taste but did not alter orofacial movements in the absence of taste, showing that our taste reactivity results described above do not reflect direct motor effects.

Food intake is increased by DAMGO in NAc or VP (see Fig. 5). Food intake was also increased by DAMGO microinjection in either NAc or VP (when combined with vehicle in the other structure) (Fig. 5). In the NAc, DAMGO microinjections in- 
creased food intake by $245 \%$ above vehicle baseline during the voluntary intake test conducted immediately after taste reactivity testing (same rats) $\left(\mathrm{NAc}_{\mathrm{DAMGO}} / \mathrm{VP}_{\text {vehicle }}, 3.36 \pm 0.58 \mathrm{~g}\right.$; $\mathrm{NAc}_{\text {vehicle }} / \mathrm{VP}_{\text {vehicle }}, 1.07 \pm 0.32 \mathrm{~g} ; F_{(1,29)}=12.13 ; p<0.01$; observed power, 0.92) (Fig. 5). Similarly, DAMGO in the VP nearly tripled food intake to $294 \%$ above vehicle levels ( $\mathrm{NAc}_{\text {vehicle }} /$ $\mathrm{VP}_{\text {DAMGO}}, 4.22 \pm 0.95 \mathrm{~g} ; \mathrm{NAc}_{\text {vehicle }} / \mathrm{VP}_{\text {vehicle }}, 1.07 \pm 0.32 \mathrm{~g}$; $F_{(1,28)}=10.56 ; p<0.01$; observed power, 0.88) (Fig. 5). The magnitude of elevation of intake produced by DAMGO did not differ statistically between NAc and VP (one-way ANOVA; NS).

The time course of eating duration, assessed at $15 \mathrm{~min}$ time bins, appeared elevated early after DAMGO microinjection in NAc or VP hotspots and remained stably elevated across the ensuing hour. Eating duration was elevated above double-vehicle levels within the first $15 \mathrm{~min}$ of the intake test $\left(F_{(1,119)}=19.49\right.$; $p<0.001 ; p<0.05$, Tukey's test) and remained elevated at 30, 45, and $60 \mathrm{~min}$ (each $p<0.05$ ). The magnitude of elevation did not differ across the four time bins $\left(F_{(3,119)}=0.40\right.$; NS). Similarly, after DAMGO microinjection in the VP hotspot, eating duration was elevated across the hour (drug, $F_{(1,119)}=16.52 ; p<0.001$ ), in a stable time-independent manner (drug/time course interaction, $F_{(3,119)}=0.46$; NS). NAc and VP hotspots did not differ in the magnitudes of increase in eating duration produced by DAMGO $\left(F_{(1,111)}=0.00\right.$; NS) or in the time course of stable elevation $\left(F_{(3,111)}=0.97\right.$; NS $)$.

\section{Differential effects of NAc versus VP naloxone blockade of DAMGO enhancements}

\section{NAc-naloxone blocks VP-DAMGO enhancement of "liking"} reactions (Fig. 4)

Naloxone microinjections in the NAc blocked the ability of DAMGO given simultaneously in the VP to enhance positive reactions to sucrose taste $(37.1 \%$ reduction from DAMGO alone; mean, $19.56 \pm 2.50 ; F_{(1,29)}=11.08 ; p<0.01$; observed power, $0.90)$ (Fig. 4). Adding naloxone in the NAc to DAMGO in the VP reduced the number of sucrose hedonic reactions to $62.9 \%$ of the level seen after VP-DAMGO alone (i.e., when VP-DAMGO was combined with NAc-vehicle), so that hedonic reactions no longer differed from the baseline level measured after vehicle in both structures $\left(F_{(1,31)}=0.24\right.$; NS; observed power, 0.08$)$ (Fig. 4). Aversive reactions to sucrose were no different than after control microinjections (double vehicle) $\left(F_{(1,31)}=1.92\right.$; NS).

Comparing NAc/VP site pairs among rats, NAc-naloxone microinjection produced the greatest blockade of hedonic reaction enhancement in the far caudal VP, especially at the same VP sites in which DAMGO most potently caused increases in hedonic reactions (e.g., inside the hedonic hotspot, in which sites $>160 \%$ DAMGO enhancement). Overall, naloxone blocked the VPDAMGO hedonic enhancement at all VP sites except two, one in central VP (paired with site in caudoventral NAc shell) and one in dorsal VP/globus pallidus (paired with site in midrostral NAc shell) (Fig. 4).

NAc-naloxone also attenuates VP-DAMGO stimulation of food intake (Fig. 5)

Adding NAc-naloxone microinjection to VP-DAMGO attenuated increases in food intake ordinarily caused by opioid stimulation of VP: rats ate less than half (46\%) the amount after naloxone was added to the combination compared with their high intake after VP-DAMGO with NAc-vehicle $\left(F_{(1,28)}=5.13, p<\right.$ 0.05 without outlier, observed power of $0.48 ; F_{(1,29)}=3.94, p=$ 0.057 with outlier, observed power of 0.54 ) (Fig. 5). NAc-naloxone attenuated VP-DAMGO effects so that intake after the com- bination was no higher than baseline intake after NAc-vehicle with VP-vehicle $\left(F_{(1,30)}=1.40\right.$; NS; observed power, 0.21$)$. The blockade of intake was thus statistically similar to the blockade of "liking" on the same test day but slightly less powerful overall. In microinjection site comparison, NAc-naloxone blocked the DAMGO enhancement of eating in most VP sites, again with the exception of two in dorsal VP and one in ventral VP. The most dorsal sites were dorsal to the VP and within the globus pallidus and appeared most resistant to NAc-naloxone blockade of both food intake and sucrose hedonic reaction enhancements.

The time course of NAc-naloxone blockade of increases in eating duration normally produced by VP-DAMGO was stable throughout the test (drug, $F_{(1,111)}=6.41, p<0.05$; drug/time course interaction, $\left.F_{(3,111)}=0.34, \mathrm{NS}\right)$.

\section{VP-naloxone blocks NAc-DAMGO enhancement of "liking" reactions (Fig. 4)}

Conversely, adding a VP-naloxone microinjection to DAMGO microinjection in the NAc blocked the enhancement of positive hedonic reactions to sucrose normally caused by NAc-DAMGO alone: the number of hedonic reactions to sucrose after VP-naloxone with NAc-DAMGO was approximately half $(57.6 \%)$ that after VP-vehicle with NAc-DAMGO $\left(F_{(1,28)}=13.17 ; p<0.01\right.$; observed power, 0.94) (Fig. 4). After VP-naloxone plus NAcDAMGO, hedonic reactions were no higher than baseline levels observed with vehicle in both sites $\left(F_{(1,29)}=1.75\right.$; NS; observed power, 0.94 and 0.28$)$. Normal aversive responses were unaffected by adding VP naloxone $\left(F_{(1,29)}=0.07\right.$; NS $)$.

The strongest blocking effect by VP-naloxone was observed from those paired with NAc sites that supported the highest DAMGO "liking" elevation, especially in the NAc hedonic hotspot in mid-dorsal medial NAc shell (Fig. 4). Overall, VP-naloxone blocked nearly all NAc-DAMGO enhancement of hedonic reactions, except for two NAc sites at the ventral edge of the dorsorostral hotspot, which supported large DAMGO enhancement of hedonic reactions over vehicle levels and stayed elevated even after VP-naloxone (Fig. 4).

\section{NAc-DAMGO stimulation of food intake persists despite VP-} naloxone (Fig. 5)

Despite blocking "liking" increases, VP-naloxone failed to block the increase in food intake caused by NAc-DAMGO $\left(\mathrm{NAc}_{\text {DAMGO }} / \mathrm{VP}_{\text {naloxone, }} 83.3 \%\right.$, mean of $3.36 \pm 0.58 \mathrm{~g}$; $\mathrm{NAc}_{\text {DAMGO }} / \mathrm{VP}_{\text {vehicle }}, 100 \%$, mean of $2.8 \pm 0.60 \mathrm{~g} ; F_{(1,30)}=0.44$; NS; observed power, 0.098) (Fig. 5). Intake after NAc-DAMGO plus VP-naloxone was still $>200 \%$ (100\% increase) of baseline levels measured after vehicle in both structures $\left(F_{(1,30)}=6.33\right.$; $p<0.05$; observed power, 0.71 ). Similarly, the duration of eating behavior was not significantly reduced by adding VP-naloxone to DAMGO in NAc, either overall $\left(F_{(1,28)}=0.02\right.$; NS; observed power, 0.052 ) or at any time point (all NS). Eating duration remained elevated above double-vehicle control levels comparably to when naloxone was not given $\left(F_{(1,30)}=6.49 ; p<0.05\right.$; observed power, 0.69).

Close inspection of intake "wanting" maps for this group (Fig. 5 ) indicated some heterogeneity across rats in VP-naloxone effects on intake ordinarily stimulated by NAc-DAMGO. Most sites $(73 \%)$ showed no change after VP-naloxone from NAcDAMGO alone, remaining within $\pm 25 \%$ of their pure DAMGO levels of food intake. However, two rats did reduce intake in half when naloxone was added to VP, but two other rats actually doubled food intake after VP-naloxone compared with NAcDAMGO alone. In summary, naloxone microinjection in VP had no overall effect on the stimulation of eating behavior normally 


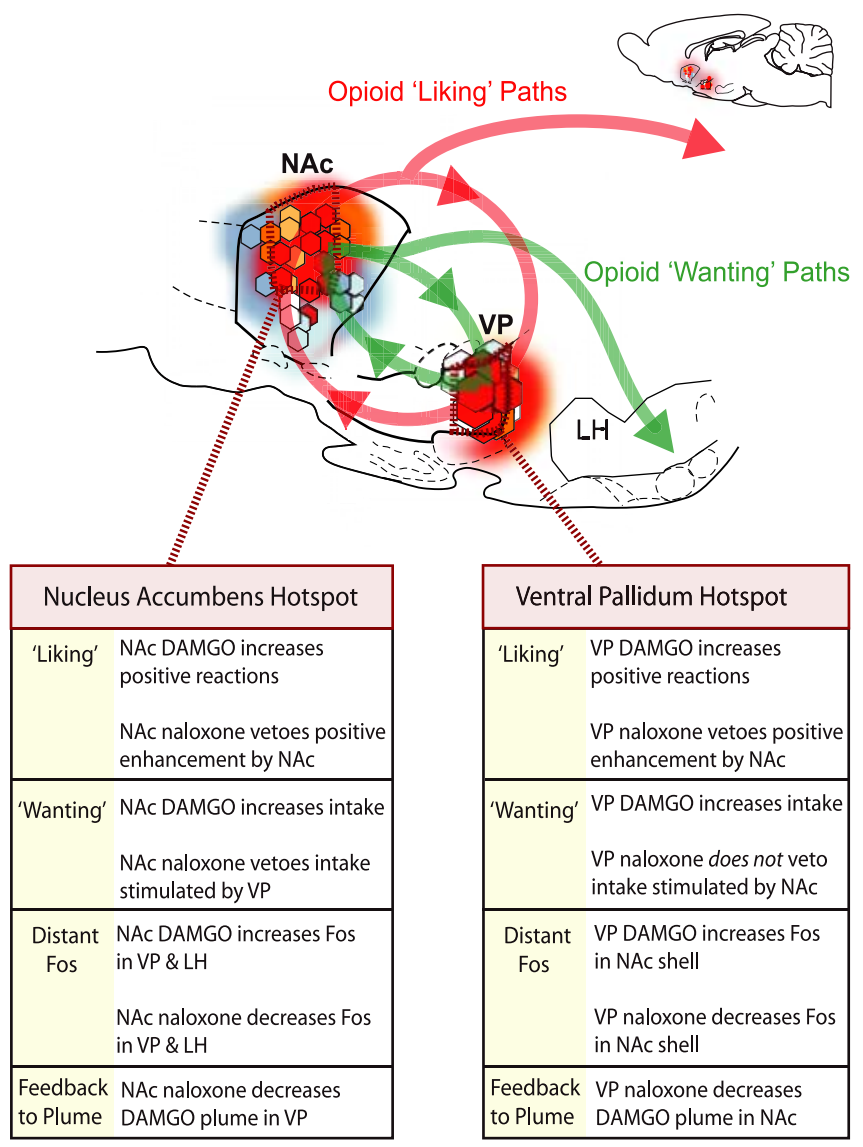

Figure 6. Summary of results and implications for NAc-VP limbic circuits of "liking" and "wanting." Opioid hotspots in NAc and VP each can elevate "liking" reactions. Opioid enhancement of "liking" recruits the other hotspot and requires simultaneous participation by both, thus forming an interactive NAc-VP loop for amplification of taste "liking" reactions (red line). In contrast, for "wanting" stimulation, NAc can act independently of VP (but not vice versa), suggesting an alternative output route NAc opioid signals to eat (green line). The expanded inset is not to scale.

caused by DAMGO in NAc (and outlier increases and decreases in either direction appeared to be balanced across rats). We therefore conclude that, although some heterogeneity may exist across individual sites, opioid activation of the NAc hotspot stimulates eating behavior and food intake in a manner that is essentially independent of the opioid state of the VP hotspot (Fig. 5).

\section{Discussion}

The findings reported here demonstrate reciprocal neurobiological interaction between opioid reward hotspots in the NAc and VP and identify for the first time separable limbic circuits for opioid amplification of reward "liking" versus "wanting" (Fig. 6). The elevation of sucrose "liking" reactions by opioid stimulation in either NAc or VP hedonic hotspot recruited participation by endogenous opioid-like neural Fos activation in the other hotspot. Conversely, opioid "liking" enhancement by either hotspot was prevented by simultaneous antagonist blockade in the other. Thus, the two hotspots interact cooperatively as a singe opioid circuit to amplify the hedonic impact of sweet reward. In contrast, elevation of "wanting" (eating behavior and intake) only required NAc stimulation, although it could be elicited by opioid activation of either hotspot. Opioid-stimulated "wanting" for food therefore has an independent route of expression from the NAc hotspot that bypasses the VP. These results have implica- tions for understanding the opioid bases of reward "liking" and "wanting" functions and for the directional flow of signals within limbic hedonic/motivational circuits (Fig. 6).

\section{Opioid "liking": mutual NAc and VP veto power}

Opioid hedonic hotspots in the NAc and VP interacted cooperatively to enhance taste "liking" (positive hedonic reactions to oral infusion of sucrose). Naloxone microinjection in the NAc blocked the increase in hedonic "liking" reactions to sucrose taste normally caused by DAMGO microinjection in the hedonic hotspot in the caudal VP. Similarly, naloxone in the VP blocked the increase in "liking" normally caused by DAMGO infusion in the hedonic hotspot in the midrostrodorsal medial shell NAc.

Our Fos observations similarly implied that $\mu$-opioid activation in either hedonic hotspot recruits endogenous opioid-like neuronal activation in the other hotspot: DAMGO microinjection in either hotspot stimulated Fos in the other hotspot, too. Furthermore, $\mu$-opioid blockade (naloxone microinjection) in one hotspot suppressed spontaneous Fos expression in the other hotspot and also fed back to shrink the local Fos plumes in the other hotspot that received DAMGO microinjection. Thus, naloxone partly reversed the stimulating hedonic vote normally cast by $\mu$-opioid stimulation in a separate hotspot rather than merely vetoing the activating effect of that vote on the larger "liking" circuit, almost equivalent to reducing the dose of a DAMGO microinjection itself. In summary, the two limbic sites acted together in a single hedonic circuit to enhance the hedonic impact of sucrose taste.

How is this interaction possible? One explanation for the ability of the NAc and VP to each "veto" the enhancement of sucrose hedonic reactions normally produced by the hotspot of the other is that "liking" elevation requires unanimous opioid activation in both the VP and NAc at the same time. For example, a DAMGO microinjection in one hotspot may produce corresponding endogenous opioid stimulation in the other as well, almost as if DAMGO microinjections had been administered to both. That possibility is supported by the observation that DAMGO microinjection in either NAc or VP hotspots caused Fos elevation in the other (as well as causing a local Fos plume around the microinjection site). An alternative explanation is that endogenous opioid neurotransmission in the nonstimulated hotspot serves a merely permissive role while staying within normal activation levels and that non-opioid activation caused Fos elevation in the other hotspot. In either case, the circuit is susceptible to naloxone disruption at more than one point within its path across multiple brain structures.

We note that studies of the NAc and caudal VP have demonstrated electrophysiological coding of taste hedonic reward (Cromwell et al., 2005; Roitman et al., 2005; Tindell et al., 2006) and reported opioid-related bidirectional interaction between NAc and VP sites (Hakan et al., 1994; Panagis et al., 1997; Napier and Mitrovic, 1999). Also, conceivably, the hedonic NAc-VP circuit identified here might also mediate the hedonic effects of opioid agents on subjective ratings of food palatability in humans (Yeomans and Gray, 1996; Drewnowski, 1997).

\section{NAc and VP opioid "wanting": NAc is independent of VP}

DAMGO microinjection in either the NAc or VP hotspots additionally increased the duration of eating behavior and grams of food consumed ("wanting") in addition to increasing "liking" reactions. However, unlike "liking" enhancement that was blocked by naloxone in either structure, only VP stimulation of eating was blocked by NAc-naloxone. In contrast, NAc stimula- 
tion of eating essentially persisted after simultaneous naloxone blockade in the VP hotspot. Thus, the NAc hotspot may exert an independent control over opioid signals to eat.

One possible mechanism might be alternative anatomical routes that bypass the VP. For example, NAc shell projects directly to the $\mathrm{LH}$, dorsomedial hypothalamus, ventral tegmental area, nucleus of the solitary tract, and central and basolateral amygdala, as well as to VP (Heimer et al., 1991; Zahm, 2000). Furthermore, eating behavior evoked by NAc-DAMGO can be blocked by simultaneous muscimol inactivation or opioid antagonism in LH, ventral tegmentum, or amygdala (MacDonald et al., 2003; Will et al., 2003; Kim et al., 2004; Will et al., 2004; Bodnar et al., 2005). The LH is especially implicated in food intake (Kelley et al., 2005), and we noted here that DAMGO infusions in the NAc shell also caused increased Fos expression in LH (besides in VP), whereas naloxone in NAc conversely suppressed spontaneous Fos below normal levels in LH (besides in $\mathrm{VP})$. In contrast, DAMGO/naloxone in VP did not change Fos in $\mathrm{LH}$. The pattern suggests that NAc has a privileged role in limbic opioid-related control of $\mathrm{LH}$ that might be relevant to eating behavior and that NAc opioid manipulations might modulate hypothalamic targets independently of VP. In other words, if alternative outputs for accumbens "wanting" signals exist, then blockade of the VP may not significantly affect NAc enhancement of eating behavior because the other "wanting" outputs remain intact. On this point, it may be relevant that the anatomical "eating zone" for opioid stimulation of food intake is much larger in the NAc than in the VP (NAc, $>2.8 \mathrm{~mm}^{3}$ volume; $\mathrm{VP},<1 \mathrm{~mm}^{3}$ ) (Kelley et al., 2002; Peciña and Berridge, 2005; Smith and Berridge, 2005) (Fig. 5), and a larger field of origin may contribute to a more distributed output network to stimulate "wanting."

\section{Limbic circuit implications}

Contemporary views of functional organization in the limbic reward circuit have emphasized serial striatopallidal circuits in which information flows mostly from the NAc to the VP (Mogenson and Yang, 1991; Kalivas and Nakamura, 1999). However, reciprocal projections from the VP to NAc also are recognized (Churchill and Kalivas, 1994), as well as independent projections from each structure (Groenewegen et al., 1993; Zahm, 2000). Our current results show that the serial schema is probably not adequate for understanding opioid amplification of reward by NAc-VP hedonic hotspots. Although opioid activation of either NAc or VP hotspots was sufficient to enhance "wanting" and "liking" for food reward, the opioid blockade effects were not consistent with a serial circuit interpretation. In particular, opioid participation simultaneously in VP and NAc was necessary to cause enhancement of taste "liking"; one without the other was insufficient, implying a loop of reciprocal interaction. In addition, the failure of VP naloxone to block NAc DAMGO eating effects suggests that the NAc has pathways to cause food "wanting" and stimulate eating behavior that bypass the VP and that opioid "wanting" circuits are different from those that amplify hedonic "liking" (Fig. 6).

\section{Conclusion}

Our results provide important new insights into the organization of limbic circuits for natural reward. The NAc and VP both contain hedonic hotspots in which opioids amplify "liking" as well as "wanting," but the present results indicate that these two effects are mediated by different limbic functional circuits. Here we showed that the NAc and VP hotspots simultaneously cooperate to amplify "liking" reactions to sucrose hedonic impact, interact- ing as a single hedonic circuit. In contrast, opioid activation in the NAc hotspot independently stimulates eating behavior ("wanting") and may in part use alternative routes to do so. Thus, NAc-VP circuits for opioid "liking" overlap with those for "wanting," but the two reward signals diverge in significant ways. From a clinical viewpoint, differential dysfunction in these separable limbic circuits of opioid reward might produce distinct patterns of change in "wanting" versus "liking" functions that could contribute to human obesity, excessive eating behavior, drug addiction, and other excessive motivational pursuits or hedonic disorders (Cooper and Kirkham, 1993; Johnson et al., 1993; Yeomans and Gray, 1996; Drewnowski, 1997; Berthoud, 2002; Kelley et al., 2005; Berridge, 2003; Koob, 2003; Robinson and Berridge, 2003; Zubieta et al., 2003; Bodnar, 2004; Insel and Fernald, 2004; Levine and Billington, 2004; Everitt and Robbins, 2005; Kalivas and Volkow, 2005; Tang et al., 2005; Hammock and Young, 2006; Peciña et al., 2006).

\section{References}

Beaver JD, Lawrence AD, van Ditzhuijzen J, Davis MH, Woods A, Calder AJ (2006) Individual differences in reward drive predict neural responses to images of food. J Neurosci 26:5160-5166.

Berridge KC (2000) Measuring hedonic impact in animals and infants: microstructure of affective taste reactivity patterns. Neurosci Biobehav Rev 24:173-198.

Berridge KC (2003) Pleasures of the brain. Brain Cogn 52:106-128.

Berthoud HR (2002) Multiple neural systems controlling food intake and body weight. Neurosci Biobehav Rev 26:393-428.

Bodnar RJ (2004) Endogenous opioids and feeding behavior: a 30-year historical perspective. Peptides 25:697-725.

Bodnar RJ, Lamonte N, Israel Y, Kandov Y, Ackerman TF, Khaimova E (2005) Reciprocal opioid-opioid interactions between the ventral tegmental area and nucleus accumbens regions in mediating mu agonistinduced feeding in rats. Peptides 26:621-629.

Bontempi B, Sharp FR (1997) Systemic morphine-induced Fos protein in the rat striatum and nucleus accumbens is regulated by $\mu$ opioid receptors in the substantia nigra and ventral tegmental area. J Neurosci 17:8596-8612.

Churchill L, Kalivas PW (1994) A topographically organized gammaaminobutyric acid projection from the ventral pallidum to the nucleus accumbens in the rat. J Comp Neurol 345:579-595.

Cooper SJ, Kirkham TC (1993) Opioid mechanisms in the control of food consumption and taste preferences. In: Opioids, Pts I and II (Herz AA, Simon EJ, eds), pp 239-262. Berlin: Springer.

Cromwell HC, Hassani OK, Schultz W (2005) Relative reward processing in primate striatum. Exp Brain Res 162:520-525.

Drewnowski A (1997) Taste preferences and food intake. Annu Rev Nutr 17:237-253.

Everitt BJ, Robbins TW (2005) Neural systems of reinforcement for drug addiction: from actions to habits to compulsion. Nat Neurosci 8:1481-1489.

Grill HJ, Berridge KC (1985) Taste reactivity as a measure of the neural control of palatability. In: Progress in psychobiology and physiological psychology (Sprague JM, Epstein AN, eds), pp 1-61. Orlando, FL: Academic.

Grill HJ, Norgren R (1978) The taste reactivity test. I. Mimetic responses to gustatory stimuli in neurologically normal rats. Brain Res 143:263-279.

Groenewegen HJ, Berendse HW, Haber SN (1993) Organization of the output of the ventral striatopallidal system in the rat: ventral pallidal efferents. Neuroscience 57:113-142.

Grove EA (1988a) Efferent connections of the substantia innominata in the rat. J Comp Neurol 277:347-364.

Grove EA (1988b) Neural associations of the substantia innominata in the rat: afferent connections. J Comp Neurol 277:315-346.

Haber SN, Groenewegen HJ, Grove EA, Nauta WJ (1985) Efferent connections of the ventral pallidum: evidence of a dual striato pallidofugal pathway. J Comp Neurol 235:322-335.

Hakan RL, Eyl C, Henriksen SJ (1994) Neuropharmacology of the nucleus accumbens: systemic morphine effects on single-unit responses evoked by ventral pallidum stimulation. Neuroscience 63:85-93. 
Hammock EA, Young LJ (2006) Oxytocin, vasopressin and pair bonding: implications for autism. Philos Trans R Soc Lond B Biol Sci 361:2187-2198.

Heimer L, Wilson RD (1975) The subcortical projections of allocortex: similarities in the neural associations of the hippocampus, the periform cortex and the neocortex. In: Golgi centennial symposium proceedings (Santini M, ed), pp 173-193. New York: Raven.

Heimer L, Zahm DS, Churchill L, Kalivas PW, Wohltmann C (1991) Specificity in the projection patterns of accumbal core and shell in the rat. Neuroscience 41:89-125.

Herrera DG, Robertson HA (1996) Activation of c-fos in the brain. Prog Neurobiol 50:83-107.

Holt AG, Newman SW (2004) Distribution of methionine and leucine enkephalin neurons within the social behavior circuitry of the male Syrian hamster brain. Brain Res 1030:28-48.

Hsu SM, Raine L, Fanger H (1981) Use of avidin-biotin-peroxidase complex $(A B C)$ in immunoperoxidase techniques: a comparison between $\mathrm{ABC}$ and unlabeled antibody (PAP) procedures. J Histochem Cytochem 29:577-580

Insel TR, Fernald RD (2004) How the brain processes social information: searching for the social brain. Annu Rev Neurosci 27:697-722.

Johnson PI, Stellar JR, Paul AD (1993) Regional reward differences within the ventral pallidum are revealed by microinjections of a mu opiate receptor agonist. Neuropharmacology 32:1305-1314.

Kalivas PW, Nakamura M (1999) Neural systems for behavioral activation and reward. Curr Opin Neurobiol 9:223-227.

Kalivas PW, Volkow ND (2005) The neural basis of addiction: a pathology of motivation and choice. Am J Psychiatry 162:1403-1413.

Kelley AE, Bless EP, Swanson CJ (1996) Investigation of the effects of opiate antagonists infused into the nucleus accumbens on feeding and sucrose drinking in rats. J Pharmacol Exp Ther 278:1499-1507.

Kelley AE, Bakshi VP, Haber SN, Steininger TL, Will MJ, Zhang M (2002) Opioid modulation of taste hedonics within the ventral striatum. Physiol Behav 76:365-377.

Kelley AE, Baldo BA, Pratt WE, Will MJ (2005) Corticostriatalhypothalamic circuitry and food motivation: integration of energy, action and reward. Physiol Behav 86:773-795.

Kim EM, Quinn JG, Levine AS, O'Hare E (2004) A bi-directional muopioid-opioid connection between the nucleus of the accumbens shell and the central nucleus of the amygdala in the rat. Brain Res 1029:135-139.

Koob GF (2003) Alcoholism: allostasis and beyond. Alcohol Clin Exp Res 27:232-243.

Levine AS, Billington CJ (2004) Opioids as agents of reward-related feeding: a consideration of the evidence. Physiol Behav 82:57-61.

Li D, Olszewski PK, Shi Q, Grace MK, Billington CJ, Kotz CM, Levine AS (2006) Effect of opioid receptor ligands injected into the rostral lateral hypothalamus on c-fos and feeding behavior. Brain Res 1096:120-124.

MacDonald AF, Billington CJ, Levine AS (2003) Effects of the opioid antagonist naltrexone on feeding induced by DAMGO in the ventral tegmental area and in the nucleus accumbens shell region in the rat. Am J Physiol Regul Integr Comp Physiol 285:R999-R1004.

Mogenson GJ, Yang CR (1991) The contribution of basal forebrain to limbic-motor integration and the mediation of motivation to action. Adv Exp Med Biol 295:267-290.

Napier TC, Mitrovic I (1999) Opioid modulation of ventral pallidal inputs. Ann NY Acad Sci 877:176-201.

Panagis G, Nomikos GG, Miliaressis E, Chergui K, Kastellakis A, Svensson TH, Spyraki C (1997) Ventral pallidum self-stimulation induces stimulus dependent increase in c-fos expression in reward-related brain regions. Neuroscience 77:175-186.

Paxinos G, Watson C (1998) The rat brain in stereotaxic coordinates. San Diego: Academic.

Paxinos G, Watson C (2005) The rat brain in stereotaxic coordinates. Burlington, MA: Elsevier Academic.
Peciña S, Berridge KC (2000) Opioid site in nucleus accumbens shell mediates eating and hedonic "liking" for food: map based on microinjection Fos plumes. Brain Res 863:71-86.

Peciña S, Berridge KC (2005) Hedonic hot spot in nucleus accumbens shell: where do $\mu$-opioids cause increased hedonic impact of sweetness? J Neurosci 25:11777-11786.

Peciña S, Smith KS, Berridge KC (2006) Hedonic hot spots in the brain. The Neuroscientist 12:500-511.

Robinson TE, Berridge KC (2003) Addiction. Annu Rev Psychol 54:25-53.

Roitman MF, Wheeler RA, Carelli RM (2005) Nucleus accumbens neurons are innately tuned for rewarding and aversive taste stimuli, encode their predictors, and are linked to motor output. Neuron 45:587-597.

Shimura T, Imaoka H, Yamamoto T (2006) Neurochemical modulation of ingestive behavior in the ventral pallidum. Eur J Neurosci 23:1596-1604

Skoubis PD, Maidment NT (2003) Blockade of ventral pallidal opioid receptors induces a conditioned place aversion and attenuates acquisition of cocaine place preference in the rat. Neuroscience 119:241-249.

Smith KS, Berridge KC (2005) The ventral pallidum and hedonic reward: neurochemical maps of sucrose "liking" and food intake. J Neurosci 25:8637-8649.

Steiner JE, Glaser D, Hawilo ME, Berridge KC (2001) Comparative expression of hedonic impact: affective reactions to taste by human infants and other primates. Neurosci Biobehav Rev 25:53-74.

Stratford TR (2005) Activation of feeding-related neural circuitry after unilateral injections of muscimol into the nucleus accumbens shell. Brain Res 1048:241-250.

Swanson LW (2000) Cerebral hemisphere regulation of motivated behavior. Brain Res 886:113-164.

Tang XC, McFarland K, Cagle S, Kalivas PW (2005) Cocaine-induced reinstatement requires endogenous stimulation of $\mu$-opioid receptors in the ventral pallidum. J Neurosci 25:4512-4520.

Tindell AJ, Smith KS, Pecina S, Berridge KC, Aldridge JW (2006) Ventral pallidum firing codes hedonic reward: when a bad taste turns good. J Neurophysiol 96:2399-2409.

Will MJ, Franzblau EB, Kelley AE (2003) Nucleus accumbens mu-opioids regulate intake of a high-fat diet via activation of a distributed brain network. J Neurosci 23:2882-2888.

Will MJ, Franzblau EB, Kelley AE (2004) The amygdala is critical for opioidmediated binge eating of fat. NeuroReport 15:1857-1860.

Woolley JD, Lee BS, Fields HL (2006) Nucleus accumbens opioids regulate flavor-based preferences in food consumption. Neuroscience 143:309-317.

Yeomans MR, Gray RW (1996) Selective effects of naltrexone on food pleasantness and intake. Physiol Behav 60:439-446.

Zahm DS (1989) The ventral striatopallidal parts of the basal ganglia in the rat. II. Compartmentation of ventral pallidal efferents. Neuroscience 30:33-50.

Zahm DS (2000) An integrative neuroanatomical perspective on some subcortical substrates of adaptive responding with emphasis on the nucleus accumbens. Neurosci Biobehav Rev 24:85-105.

Zahm DS, Zaborszky L, Alones VE, Heimer L (1985) Evidence for the coexistence of glutamate decarboxylase and Met-enkephalin immunoreactivities in axon terminals of rat ventral pallidum. Brain Res 325:317-321.

Zhang M, Kelley AE (2000) Enhanced intake of high-fat food following striatal mu-opioid stimulation: microinjection mapping and fos expression. Neuroscience 99:267-277.

Zhang M, Gosnell BA, Kelley AE (1998) Intake of high-fat food is selectively enhanced by mu opioid receptor stimulation within the nucleus accumbens. J Pharmacol Exp Ther 285:908-914.

Zubieta JK, Ketter TA, Bueller JA, Xu Y, Kilbourn MR, Young EA, Koeppe RA (2003) Regulation of human affective responses by anterior cingulate and limbic mu-opioid neurotransmission. Arch Gen Psychiatry 60:11451153. 